\title{
Prediction of academic achievement based on learning strategies and outcome expectations among medical students
}

\author{
Sakineh Nabizadeh', Sepideh Hajian ${ }^{2^{*}}$, Zohre Sheikhan ${ }^{2}$ and Fatemeh Rafiei ${ }^{3}$
}

\begin{abstract}
Background: One of the most important indicators of the effectiveness of teaching can be the academic achievement of learners, which can be influenced by different factors such as learning methods and individual motivations. The purpose of this study was to determine the ability of predicting academic achievement based on learning motivation strategies and outcome expectations based on a theoretical model.

Methods: This descriptive-analytic study was conducted with the participation of 380 male and female students of nine faculties of medical sciences of Shahid Beheshti University of Tehran. Multi-stage sampling along with the questionnaire of motivational strategies for learning and student outcome expectation scale were used for data collection. The college grade point average (CGPA) of students' past grades was considered as the academic performance variable. Data analysis was performed using Structural Equation Modeling (SEM) in AMOS software.

Results: The mean score of the structure of learning strategies, motivational strategies, outcome expectations, and students' GPA did not show significant statistical differences in terms of gender, marital status, residence location, field of study, and educational level. There was a direct and significant relationship between the motivational strategies' structures $(R=0.193, p<0.001)$ as well as learning strategies $(R=0.243, p<0.001)$ and the CGPA, while there was no relationship between outcome expectations and CGPA. Path analysis revealed that self-regulating learning strategies and motivational strategies can predict the academic achievement of these students.
\end{abstract}

Conclusions: Considering the importance of active and independent learning among medical students, it is necessary for lecturers to use interactive and student-oriented patterns of teaching. Also, students should become familiar with self-regulating learning skills to better understand the information they receive.

Keywords: Academic achievement, Learning strategies, Outcome expectations

\section{Background}

One of the performance measures of any educational system is the students' academic achievement. Academic achievement is the ability to prove academic achievement in the acquisition of the planned outcome [1]. Many scholars emphasize the impact of mental and cognitive abilities on academic achievement; however, having high intelligence does not guarantee academic achievement, and individuals need to be aware of their learning styles

\footnotetext{
* Correspondence: s.hajian@sbmu.ac.ir; hajian74@yahoo.com

${ }^{2}$ Department of Midwifery and Reproductive Health, Faculty of Nursing and

Midwifery, Shahid Beheshti University of Medical Sciences, Tehran, Iran
}

Full list of author information is available at the end of the article
[2]. The learning styles are methods of learning applied by students in achieving, analyzing, and internalizing their newly acquired knowledge [3].

Students of medical sciences encounter massive information to be learned, and more importantly, to be applied in clinical practice. For this reason, as lifelong learners, they need to utilize efficient learning strategies that work well and make voluminous information durable [4].

The learning strategies differ in effectiveness and practicality, although they have common characteristic including meaningful learning or learning with understanding. This happens when students integrate new acquired information with their existing knowledge. Meanwhile, there are a few learning methods available

(c) The Author(s). 2019 Open Access This article is distributed under the terms of the Creative Commons Attribution 4.0 International License (http://creativecommons.org/licenses/by/4.0/), which permits unrestricted use, distribution, and reproduction in any medium, provided you give appropriate credit to the original author(s) and the source, provide a link to the Creative Commons license, and indicate if changes were made. The Creative Commons Public Domain Dedication waiver (http://creativecommons.org/publicdomain/zero/1.0/) applies to the data made available in this article, unless otherwise stated. 
to medical students to manage all information in mind for academic improvement [5]. With a review of the existing theories on teaching and learning, one can see that individuals behave differently in the same situations. One of the reasons for this situation is their learning strategies, with the extent of employing learning strategies and the underlying individual [2], psycho-emotional, and environmental factors affecting the academic achievement of learners [6].

One of the theories in this field is the Social Cognitive Career Theory (SCCT), developed based on Bandura's general social cognitive theory to predict the success and performance of individuals with regard to their cognitive, psychological, and behavioral aspects. The SCCT model emphasizes the role of individual abilities, self-efficacy beliefs, outcome expectations, and extrinsic factors in achieving academic or professional success [7]. Accordingly, learning is an active cognitive process in the mind which is influenced by factors such as age, personality traits such as compliance with environmental conditions, attendance in the classroom [8], positive interaction with others [9], intrinsic and extrinsic motivational goals, characteristics of the study approach, and individual self-regulating learning strategies [6].

Self-regulated strategies for learning are defined as the ability to learn based on individual endeavors; cognitive and metacognitive self-regulations are considered as an example of these strategies developed by Bandura [10]. Cognitive learning strategies include mental review, expanding and content-organizing; finally, metacognitive learning strategies include critical thinking, self-learning, organizing, self-controlling, and self-assessment [11].

With regards to these strategies, Zimmerman stated that "learners, rather than relying on lecturers, parents, or other educational authorities, manage their own efforts", which will lead the learners to adopt their way of studying and improve their performance. Cognitive strategies for learners include mental review, semantic expansion, and information-organizing. On the other hand, individuals may use metacognitive strategies to monitor, guide and, if necessary, modify their cognitive strategies, which include planning, supervising and organizing the learning process [12]. In this regard, self-regulating learners are those who have planning, content-organizing, self-learning, self-controlling, and self-evaluating capabilities [11].

On the other hand, motivational self-regulation refers to the active use of motivational strategies that enhance learning; during the learning process, learners find themselves competent, self-confident, and independent and can plan, organize, self-control, and self-assess for learning [12].

However, the results of research in using cognitive and metacognitive strategies are contradictory regarding the academic achievement of learners, which is attributed to motivational stimuli or individual's perceptions of their ability or outcome expectations in the future [13, 14]. According to Bandura's social cognitive theory, the outcome expectations predict behaviors, meaning that these expectations can affect the person's ultimate behavior using positive motivators or negative consequences that reduce motivation [15].

The results of studies on the role of learning strategies and learning expectations are also contradictory. For example, among students of United Arab Emirates (UAE) universities, self-efficacy and metacognitive strategies were the strongest predictors of academic achievement [16], while in a study in Iran, self-regulating strategies of learning did not show any significant difference [17]. Also, a study on the effect of using self-regulating strategies on the abilities of learners who study through virtual education showed that the use of these strategies alone was not effective in improving their learning [18].

However, studies on the relationship between learning strategies and academic performance of medical students are limited. A review study on self-regulated learning in the medical students' learning environment suggested that novice students in pre-clinical environment need more support from others, specifically from seniors, to help them formulate learning objectives and handle the new learning environment [19].

The purpose of this study was to determine the predictability of academic achievement based on learning strategies and outcome expectations based on social cognitive theory of Bandura among preclinical students of Shahid Beheshti University of Medical Sciences in Tehran in 2017. With regard to the research goal, the following hypotheses were developed:

1. There is a significant relationship between learning strategies as well as motivational strategies and academic achievement;

2. There is a significant relationship between the outcome expectations and academic achievement;

3. There is a significant relationship between extrinsic individual factors and academic achievement;

4. Learning strategies and outcome expectations can predict academic achievement among medical students.

\section{Method}

\section{Participants and inclusion/exclusion criteria}

This descriptive-analytic study was conducted on a sample of undergraduate female and male students of medical sciences in Shahid Beheshti University of Tehran. The inclusion criteria were as follows:

1- Being an undergraduate student of years 2, 3, or 4 in one of medical sciences fields (pre-clinical for medical 
students), 2- Based on the self-report of the students, not having any of the following experiences in the last year: separation or divorce (themselves or their parents), death of a family member, addiction to drug and psychotropic drugs, severe illness, or severe family crises. In any stage of the study, in case any participant decided to abandon the collaboration, he/she would have been omitted from the study.

\section{Sampling and sample size}

Sampling was done as multi-stage. Initially, the total population of undergraduate students in nine faculties of Medical Sciences of Shahid Beheshti University of Tehran was obtained from the Academic Administration Deputy $(N=2857)$. Then, each faculty was considered as a cluster and based on each cluster's population, a quota was allocated to them. In this step, a quota sampling procedure with field of study was applied as the main quota of the control variable. Finally, convenience sampling was performed on each faculty from eligible students until the specified sample size was over. The initial sample size was calculated using the Cochran formula as below:

$$
\begin{aligned}
& \mathrm{N}=\frac{\frac{Z_{\alpha}{ }^{2} p q}{d^{2}}}{1+\frac{1}{N}\left(\frac{z_{\alpha}{ }^{2} p q}{d^{2}}-1\right)} \\
& =\frac{\frac{\left(1.96^{2} 0.5 \times 0.5\right.}{(0.05)^{2}}}{1+\frac{1}{2857}\left(\frac{\left(1.96^{2}\right)}{(0.5 \times 0.05)^{2}}-1\right)}=339 \\
& \alpha=0.05 . \mathrm{d}=0.05, \mathrm{p}=0.5, \mathrm{q}=0.5, \mathrm{Z} \alpha=1.96, \mathrm{~N}=2857
\end{aligned}
$$

The final sample size was calculated to be 380 people considering a loss of $10 \%$ and a significance level of less than 0.05 .

\section{Study instruments}

Since the theoretical framework of this research was based on the SCCT performance model, the most important structures of this model were extracted including cognitive learning abilities, self-efficacy beliefs, outcome expectations, as well as individual goals and factors. Then, their relationship with students' academic achievement was investigated through appropriate tools. A self-administered questionnaire, consisting of demographic information, learning strategies, and outcome expectations, was used based on the study objectives.

The first section of the questionnaire evaluated the extrinsic individual factors, i.e. demographic characteristics, and variables indicating intrinsic goals such as previous interest and satisfaction with the field of study, study hours per week, and hours spent for work other than study.

The second section, i.e. motivational strategies for learning questionnaire (MSLQ), was used in its 81-item form in this study. This scale was first developed by Pintrich and his colleagues in 1990 for assessing college students' motivational orientations and their utilization of different learning strategies for teachers or researchers in education [20]. In addition, The MSLQ may be adapted to the researcher's or teacher's need on how to enhance their students' levels of motivation and learning strategies. Also, academic members can use the MSLQ to receive feedback on their students and to support them regarding course adjustments. Meanwhile, students can also use it for self-assessing their abilities and weaknesses in their courses [21].

The MSLQ is based on the general cognitive and social cognitive theory of Bandura regarding motivational and learning strategies. This instrument has essentially two sections: i) motivation section; ii) learning strategies. The first section consists of 31 items which assess:

1. students' goals and value beliefs for a course, as value component, with 14 items including intrinsic orientation (4items), extrinsic evaluation (4 items), and task value (6 items);

2. students' beliefs about their skill to succeed along with their anxiety about tests in a course, as expectancy component, with 17 items including, controlling learning beliefs ( 4 items), self-efficacy ( 8 items) and test anxiety (5 items).

The second section includes 50 items on

1. students' use of different self-regulated strategies, as cognitive and metacognitive strategies, with 31 items including rehearsal (4items), elaboration (6items), organization (4 items), critical thinking (5 items) and metacognitive self-regulation (12 items);

2. student management of different resources, as resource management strategies, with 19 items including time and study environment (8 items), effort regulation (4 items), peer learning (3 items), and seeking help (4 items).

Students rate themselves on a seven-point Likert scale from "not at all true of me" to "very true of me." Scales are constructed by taking the mean of the items making up that scale. Scores can range from 81 to 567 in total. However, Pintrich and his colleagues did not provide norms for the MSLQ; rather it has been designed to be used at the course level. They assumed that students' 
responses to the questions could vary and the same individual might report different levels of motivation or strategy use depending on the course [20].

In the third section, student outcome expectations scale (SOES) was used. It was designed and developed by Betz and Voyten in 1997 to determine students' beliefs concerning the performance of a behavior. The original version of SOES consists of 13 items defined in three factors. This scale measures students' responses in a 4-point range on a Likert scale [22].

The psychometric properties analysis of the MSLQ has previously been performed, and the overall internal consistency reliability, provided by Pintrich et al., has been found to be sufficient (more than 0.7 for two main sections) [21]. In addition to English, the MSLQ has been translated into other languages [23] including Persian [24]. The reliability of this instrument has been confirmed, and its internal consistency have proved to be acceptable for all MSLQ items together (Cronbach's alpha $\geq 0.80$ ) and every individual domain (Cronbach's alpha $\geq 0.70)$ [25].

The psychometric properties analysis of the SOES in an Iranian methodological study has been confirmed by confirmatory factor analysis through the Principal Component Analysis of 11 items and 4 factors (Table 2). The Cronbach's alpha coefficients across the four sub-scales were between 0.65 and 0.79 , indicating that the questionnaire had acceptable internal consistency [26].

\section{Data collection}

After explaining the goals of the study and obtaining written informed consent letter from the students, the questionnaires were provided to them. At the beginning of administration of the questionnaires, the researcher (first author) explained about each section of the instrument in detail and emphasized the importance of students' responses that can offer helpful suggestions to the students on how to enhance their levels of learning motivation and strategies. Further, if necessary, they could receive feedback from the researcher. In addition, they were informed that they would not be marked or judged at all; rather the result could be adapted to the instructor's academic educational needs. So, they were asked to rate themselves by answering the whole items in papers completely and not to leave any item unanswered. In case only less than $5 \%$ of the items were not answered, the score of "not sure" option would have been assigned to those items, while if more than $5 \%$ of the items were left unanswered, that questionnaire would have been omitted from the study.

The questionnaires were administered in regular classrooms. The completion of the questionnaire took an average of $20 \mathrm{~min}$ per person. The CGPA in all past semesters was considered as the variable of academic achievement. Data collection was performed within 2 months.

\section{Statistical analysis}

To test the research hypotheses, raw data were analyzed using SPSS 22 and then entered into the AMOS software. Using structural equation modeling (SEM), the relationship between the studied variables and the students' academic achievement was investigated. The significance level was considered to be less than 0.05 (Additional file 1).

\section{Results}

\section{Descriptive information}

In this research, 380 students from different fields of medical sciences were studied. The response rate was $100 \%$ and no questionnaires were dropped. The average age of respondents was $21.35 \pm 2.91$ years, with the

Table 1 Demographic characteristics of the participants ( $N=$ 380)

\begin{tabular}{|c|c|c|}
\hline characteristics & $\mathrm{n}$ & Percent (\%) \\
\hline \multicolumn{3}{|l|}{ gender } \\
\hline female & 229 & 60.3 \\
\hline male & 151 & 39.7 \\
\hline \multicolumn{3}{|l|}{ grade } \\
\hline Second & 168 & 44.2 \\
\hline Third & 158 & 41.6 \\
\hline Forth and more & 54 & 14.2 \\
\hline \multicolumn{3}{|l|}{ Field of study } \\
\hline Medicine & 87 & 22.9 \\
\hline Dentistry & 51 & 13.4 \\
\hline Pharmacy & 32 & 8.4 \\
\hline Paramedicine & 143 & 37.6 \\
\hline Midwifery & 17 & 4.5 \\
\hline Nursing & 17 & 4.5 \\
\hline Anesthesiology & 16 & 4.2 \\
\hline Operation room & 17 & 4.5 \\
\hline \multicolumn{3}{|l|}{ Marital status } \\
\hline Single & 359 & 94.5 \\
\hline Married & 20 & 5.2 \\
\hline other & 1 & 0.3 \\
\hline \multicolumn{3}{|l|}{ residence } \\
\hline parents'/own home & 170 & 44.8 \\
\hline dormitory & 208 & 54.7 \\
\hline Relatives' home & 2 & 0.5 \\
\hline \multicolumn{3}{|l|}{ Second vocation } \\
\hline Yes & 49 & 12.9 \\
\hline no & 331 & 87.1 \\
\hline
\end{tabular}


youngest being 18 and the eldest being 47 years old. Some demographic features of the participants are presented in Table 1. Comparison of the CGPA of students did not show any significant difference in terms of the variables of gender, field of study, educational level, marital status, employment status, and place of residence.

The distributions of the average scores for each subscale of the questionnaires and the CGPA of students in the previous semesters are reported in Table 2.

A review of the distribution of these variables indicated normal data distribution. The average scores of the structures of learning strategies, motivational strategies, outcome expectations, and their sub-structures as well as the CGPA of students did not show significant statistical differences in terms of gender, marital status, permanent and current place of residence, field of study, and educational level.

\section{Testing the Study's hypotheses}

The calculation of Pearson correlation coefficients between study variables and the CGPA of students $(P<$ $0.05)$ revealed a direct linear and positive correlation between the motivational strategies and learning strategies plus most of their sub-structures and CGPA students, confirming the first hypothesis of the study. However, there was no such relationship between the outcome expectations and the CGPA. Therefore, the second hypothesis of the research is rejected.

Also, regarding the third hypothesis of the study, merely a significant relationship was confirmed between hours of study per week (positive linear) and hours spent on work other than education (negative linear) with CGPA. However, the CGPA of students showed no significant difference in terms of age, gender, parent's

Table 2 Distribution of questionnaires' scores and their correlation coefficients to students' grade point average (GPA)

\begin{tabular}{|c|c|c|c|c|}
\hline Variable & Mean $\pm(S, D)$ & Min \& Max & Default Min \& Max & R-correlation coefficient \\
\hline MOTIVATIONAL STRATEGIES & $157.62(41.35)$ & $31-217$ & $31-217$ & $0.193^{b}$ \\
\hline Value component & 71.9 (15.76) & $19-98$ & $14-98$ & $0.201^{b}$ \\
\hline Intrinsic orientation & 21.08(5.19) & $4-28$ & $4-28$ & $0.162^{b}$ \\
\hline Extrinsic evaluation & $19.18(5.41)$ & $4-28$ & $4-28$ & $0.109^{\mathrm{a}}$ \\
\hline Task value & $31.12(7.13)$ & $9-42$ & $6-42$ & $0.156^{\mathrm{b}}$ \\
\hline expectancy component & $85.79(13.24)$ & $17-119$ & $17-129$ & $0.150^{\mathrm{a}}$ \\
\hline Control of Learning Beliefs & $22.57(4.05)$ & $4-28$ & $4-28$ & $0.033(N . S)$ \\
\hline Self-Efficacy & $41.92(8.36)$ & $8-56$ & $8-56$ & $0.294^{b}$ \\
\hline Test Anxiety & $21.11(6.05)$ & $5-35$ & $5-35$ & $-0.112^{b}$ \\
\hline LEARNING STRATEGIES & $221.62(38.35)$ & $101-340$ & $5-350$ & $0.243^{b}$ \\
\hline Cognitive and Metacognitive Strategies & $138.45(28.36)$ & $46-211$ & $31-217$ & $0.244^{b}$ \\
\hline Rehearsal & $16.62(4.98)$ & $4-28$ & $4-28$ & $0.193^{b}$ \\
\hline Elaboration & $27.62(6.9)$ & $6-42$ & $6-42$ & $0.228^{b}$ \\
\hline Organization & $18.46(5.4)$ & $4-28$ & $4-28$ & $0.230^{\mathrm{b}}$ \\
\hline Critical Thinking & $22.78(5.73)$ & $5-35$ & $5-35$ & $0.207^{b}$ \\
\hline Metacognitive Self-Regulation & $52.95(10.05)$ & $27-78$ & $12-84$ & $0.196^{\mathrm{b}}$ \\
\hline Resource Management Strategies & $83.17(16.33)$ & $19-129$ & 19-133 & $0.190^{\mathrm{b}}$ \\
\hline Time and Study Environment & $36.79(6.56)$ & $8-52$ & $8-56$ & $0.124^{a}$ \\
\hline Effort Regulation & $16.51(4.04)$ & $4-28$ & $4-28$ & $0.043(N . S)$ \\
\hline Peer Learning & $11.57(4.15)$ & $3-21$ & $3-21$ & $0.177^{b}$ \\
\hline Help Seeking & $17.72(4.35)$ & $4-28$ & $4-28$ & $0.186^{b}$ \\
\hline OUTCOME EXPECTANCY & $33.76(6.71)$ & $11-43$ & $11-44$ & 0.049 (N.S) \\
\hline Future orientation & $12.39(3.00)$ & $4-19$ & $4-16$ & $0.048(N . S)$ \\
\hline Job satisfaction & $9.39(2.62)$ & $3-12$ & $3-12$ & $0.057(\mathrm{~N} . \mathrm{S})$ \\
\hline Personal expectations & $5.97(1.94)$ & $2-8$ & $2-8$ & $-0.048(N . S)$ \\
\hline Personal trust & $7.00(1.50)$ & $2-8$ & $2-8$ & $0.084(N . S)$ \\
\hline Vacation hours/week & $20.88(2.47)$ & - & - & $-0.360^{\mathrm{a}}$ \\
\hline Study hours/week & $59.90(3.50)$ & - & - & $0.256^{\mathrm{b}}$ \\
\hline Grade point average (GPA) & $16.42(1.30)$ & $12-19.15$ & $0-20$ & - \\
\hline
\end{tabular}

less than $0.05{ }^{\mathrm{b}}$ less than 0.001 
education level, marital status, employment status (other than education), field of study, previous interest in the field of study, and satisfaction with the field of study (Table 2).

In order to test the fourth hypothesis and to determine the accuracy of the conceptual model of the research, considering the available data, structural equation modeling using the maximum probability method was utilized with the help of AMOS software.

When examining the structural equation, the fitness between the hypothesis model and study data is an important component. Accordingly, the goodness of fit indices was evaluated. The results in Table 3 indicate that this model is acceptable in terms of all indicators of goodness of fit and research data.

In Fig. 1, the conceptual model of the research, along with standard factor loads, shows the relationship between learning strategies, motivational strategies, as well as outcome expectations and the CGPA of students, indicating that among these three variables, the learning strategies directly affect the CGPA.

In this regard, the direct effects of research variables and their significance for each of the direct paths of the conceptual model of the research were examined. The results revealed that among the three main variables, i.e. learning strategies, motivational strategies, and outcome expectations, the greatest impact belonged to learning strategies. In other words, having examined the simultaneous effect of each of these variables as an independent variable on the CGPA, the standard coefficients of the model indicated that the variable of learning strategies has a greater effect on the increase in the CGPA

Table $\mathbf{3}$ Indices of goodness of fit for conceptual model of the research

\begin{tabular}{|c|c|c|}
\hline Fitness criteria & approximate fit indices & Model's index value \\
\hline $\mathrm{CMIN}^{\mathrm{a}}$ & $0<\mathrm{CMIN}<2 \mathrm{df}$ & 82.311 \\
\hline$d f^{b}$ & & 37 \\
\hline$P^{c}$ & $0.01<p \leq 0.05$ & 0.001 \\
\hline CMIN/df & $0<\mathrm{CMIN} / \mathrm{df}<2$ & 2.225 \\
\hline RMSEA $^{d}$ & $0 \leq$ RMSEA $\leq 0.05$ & 0.057 \\
\hline$P($ RMSEA< 0.05$)$ & $0.1<p \leq 1$ & 0.232 \\
\hline $\mathrm{GFI}^{\mathrm{e}}$ & $0.95 \leq \mathrm{GFI} \leq 1$ & 0.961 \\
\hline$\left.A G F\right|^{f}$ & $0.9 \leq \mathrm{AGFI} \leq 1$ & 0.930 \\
\hline $\mathrm{NFI}^{\mathrm{g}}$ & $0.95 \leq \mathrm{NFI} \leq 1$ & 0.964 \\
\hline$T L I^{h}$ & $0.97 \leq \mathrm{TLI} \leq 1$ & 0.969 \\
\hline$|F|^{i}$ & $>0.9$ & 0.980 \\
\hline $\mathrm{CFP}^{\mathrm{j}}$ & $0.97 \leq \mathrm{CFI}<1$ & 0.979 \\
\hline $\mathrm{RFI}^{\mathrm{k}}$ & $>0.6$ & 0.946 \\
\hline
\end{tabular}

${ }^{\mathrm{a} Q} \mathrm{Q}-\mathrm{Squared},{ }^{\mathrm{b}}$ degree of Freedom, ${ }^{\mathrm{C}}$ Level of significance, ${ }^{\mathrm{d}}$ Root Mean Square Error of Approximation, ${ }^{e}$ goodness of fit index, ${ }^{f}$ adjusted goodness of fit index ${ }^{9}$ Nonnormed Fit Index, ${ }^{\text {h }}$ Tucker-Lewis Index, ${ }^{i}$ Incremental Fit Index,

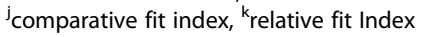

and, in turn, on academic achievement of the students (Table 4).

In addition, the study of direct and indirect effects of the model demonstrated that the greatest effect belonged to cognitive and metacognitive strategies, followed by the variable of valuation, which has an indirect positive effect on academic achievement (Table 5).

\section{Discussion}

The findings of this study suggested that cognitive and metacognitive learning strategies and motivational strategies are predictors of academic achievement of students. In other words, students who use self-regulating and motivational learning strategies have a higher academic performance. Stating that there is a significant relationship between academic achievement and use of self-regulating learning strategies, Zimmerman suggested that although most learners use these strategies for learning, what distinguish them from each other are their awareness of how to use them and having a motivation for using them [12]. A review of 14 articles assessing self-regulated strategies of learning indicated that this type of learning is associated with academic achievement and success in clinical skills in the future [19].

Students participating in this study had above average levels of learning strategies and motivational strategies. It suggests that students try to actively learn information, and experience and direct their own learning, instead of relying on the classroom and instructional environment. One of the reasons can be the nature of educational curriculum in medical sciences and the critical role of clinical professions in dealing with the health of patients. In addition to focusing, practicing and planning, self-learning, memorizing, and mentally reviewing tips and points and asking for peer help in obtaining favorable grades in exams, it is necessary for these students to apply this information in real-life context and to obtain clinical competencies. These findings are consistent with Mukhtar et al.'s results who concluded that the assistants in different medical fields who feel more attached to their profession and, as a result, to other people, use more self-regulation skills for learning and had a higher academic performance [27].

Among the SCCT structures examined, the students' academic achievement in this study was most influenced, in terms of self-regulating learning strategies, by the changes in organizing and expansion strategies, which is in line with the results obtained by Muwonge et al. (2018). They stated that the organizing strategy is one of the best and most complete types of learning strategies [14]. In addition, the strategy of semantic expanding through addition of new information to link to previous information should always be considered by lecturers in teaching skills. 


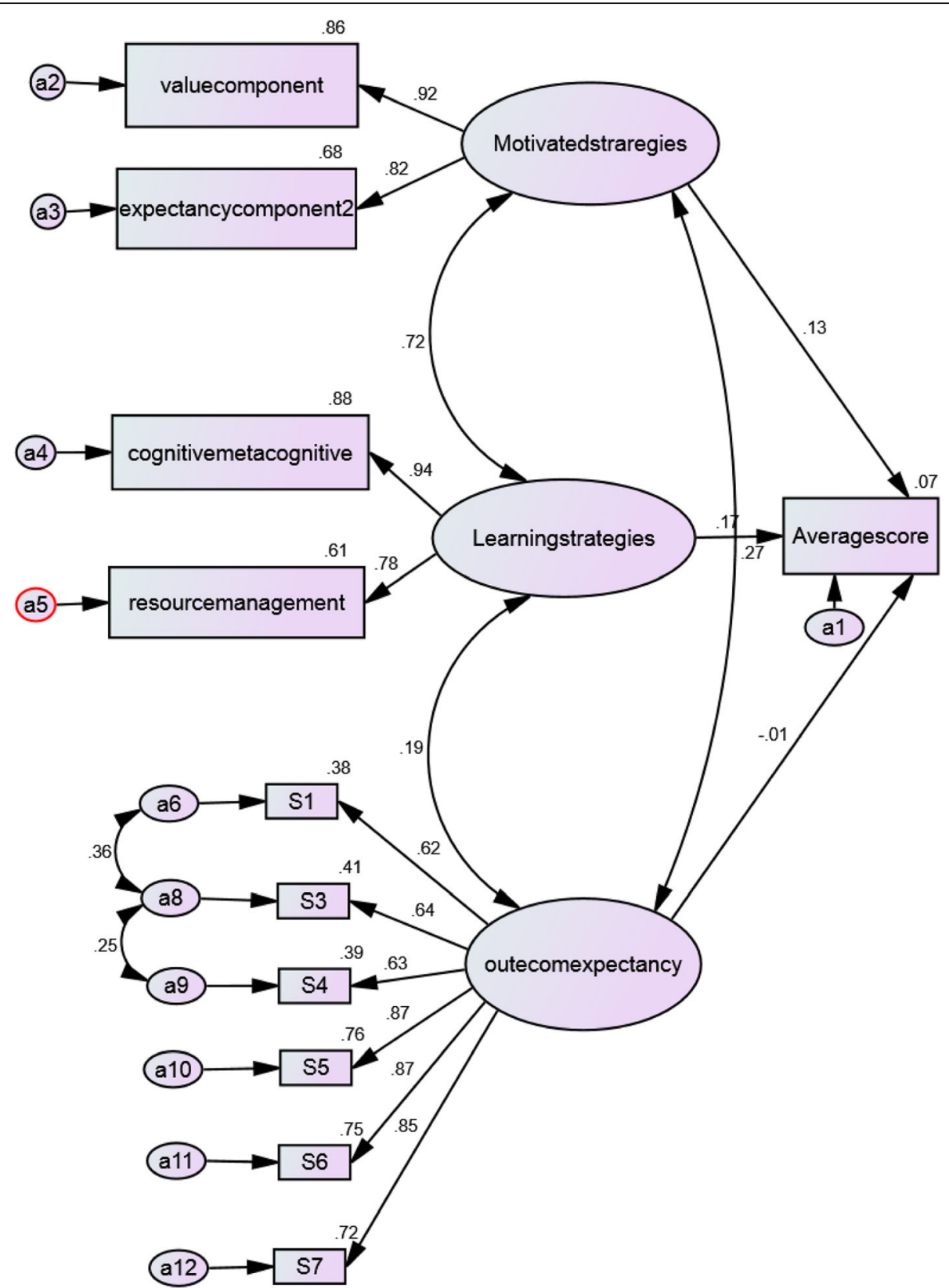

Fig. 1 structured relationships model between motivated strategies, learning strategies, outcome expectations and students' college grade point average (GPA)

Furthermore, motivational strategies indirectly played an effective role in the student's academic achievement in this study. This finding suggests that students, in addition to having an interest in academic education, had a great incentive to enter their field of study; however, only motivation cannot predict the proper academic performance. In line with the findings of this study, Muwonge et al., in their study on the self-regulation and motivational learning strategies among 1081 students from seven universities in Uganda, stated that motivational strategies influenced students' academic achievement only through affecting critical thinking strategies and organizing skills. Therefore, educational interventions to improve the academic performance of students should focus on increasing the motivation of learners and enhance their use of cognitive learning strategies [14]. Thus, it can be said that students who have a high motivation to obtain a better score demonstrate more effort, better organize their information, have better time management, and show better performance [27]. 
Table 4 significance analysis of path coefficients of directed effect on study conceptual model

\begin{tabular}{|c|c|c|c|c|c|c|c|}
\hline \multicolumn{3}{|l|}{ path } & \multirow{2}{*}{$\begin{array}{l}\text { Non-standardized factor } \\
\text { loading } \\
1\end{array}$} & \multirow{2}{*}{$\begin{array}{l}\text { standardized factor } \\
\text { loading } \\
0.823\end{array}$} & \multirow{2}{*}{$\begin{array}{l}\text { Standard error } \\
\text { estimation }\end{array}$} & \multirow{2}{*}{$\begin{array}{l}\mathrm{T} \\
\text {-value }\end{array}$} & \multirow{2}{*}{$\begin{array}{l}p- \\
\text { value }\end{array}$} \\
\hline $\begin{array}{l}\text { Motivated } \\
\text { strategies }\end{array}$ & $\rightarrow$ & $\begin{array}{l}\text { Expectancy } \\
\text { component }\end{array}$ & & & & & \\
\hline Motivated strategie & $\rightarrow$ & Value component & 1.504 & 0.925 & 0.08 & 17.093 & 0.0001 \\
\hline Learning strategies & $\rightarrow$ & $\begin{array}{l}\text { Resource } \\
\text { management }\end{array}$ & 1 & 0.784 & & & \\
\hline Learning strategies & $\rightarrow$ & $\begin{array}{l}\text { Cognitive } \\
\text { metacognitive }\end{array}$ & 2.364 & 0.937 & 0.154 & 15.339 & 0.0001 \\
\hline $\begin{array}{l}\text { Outcome } \\
\text { expectancy }\end{array}$ & $\rightarrow$ & S1 & 1 & 0.619 & & & \\
\hline $\begin{array}{l}\text { Outcome } \\
\text { expectancy }\end{array}$ & $\rightarrow$ & S3 & 1.001 & 0.640 & 0.076 & 13.206 & 0.0001 \\
\hline $\begin{array}{l}\text { Outcome } \\
\text { expectancy }\end{array}$ & $\rightarrow$ & S4 & 1.046 & 0.626 & 0.101 & 10.374 & 0.0001 \\
\hline $\begin{array}{l}\text { Outcome } \\
\text { expectancy }\end{array}$ & $\rightarrow$ & S5 & 1.416 & 0.872 & 0.107 & 13.181 & 0.0001 \\
\hline $\begin{array}{l}\text { Outcome } \\
\text { expectancy }\end{array}$ & $\rightarrow$ & S6 & 1.366 & 0.866 & 0.104 & 13.132 & 0.0001 \\
\hline $\begin{array}{l}\text { Outcome } \\
\text { expectancy }\end{array}$ & $\rightarrow$ & S7 & 1.382 & 0.846 & 0.107 & 12.947 & 0.0001 \\
\hline Learning strategies & $\rightarrow$ & Average score & 0.019 & 0.167 & 0.010 & 1.965 & 0.049 \\
\hline $\begin{array}{l}\text { Outcome } \\
\text { expectancy }\end{array}$ & $\rightarrow$ & Average score & 1.028 & 0.013 & 0.120 & -0.232 & 0.817 \\
\hline $\begin{array}{l}\text { Motivated } \\
\text { strategies }\end{array}$ & $\rightarrow$ & Average score & 0.019 & 0.129 & 0.013 & 1.481 & 0.139 \\
\hline
\end{tabular}

In a study by Wibrowski, the freshmen students undergoing Skills Learning Support Program (SLSP) had a higher level of study and motivation skills and better academic achievement indicators compared to their peer students who were not involved in this program [1]. Griffin et al. suggested that awareness of metacognitive strategies and promotion of study skills have a positive effect on academic achievement and intrinsic motivation as self-regulating learners will be able to use different means to acquire active learning experiences and, whenever necessary, organize learning strategies according to their requirements, task features, and context-specific conditions [28].

The findings of this study suggested that the effect of self-efficacy beliefs on academic achievement is significant and worthy of discussion. The findings from two different studies on medical students in Turkey suggested that most medical students used self-regulation skills and believed in their ability to learn effectively [29, 30]. [23, Further, Kek and Huijser concluded that higher

Table $\mathbf{5}$ The sum of the direct and indirect effects of the study's model on students' academic chievement

\begin{tabular}{|c|c|c|c|c|c|}
\hline \multicolumn{3}{|l|}{ path } & \multirow{2}{*}{$\begin{array}{l}\text { Direct effects } \\
-0.013\end{array}$} & \multirow{2}{*}{$\begin{array}{l}\text { Indirect effects } \\
0\end{array}$} & \multirow{2}{*}{$\begin{array}{l}\text { Total effects } \\
-0.013\end{array}$} \\
\hline Outcome expectancy & $\rightarrow$ & Average score & & & \\
\hline Learning strategies & $\rightarrow$ & Average score & 0.167 & 0 & 0.167 \\
\hline Motivated strategies & $\rightarrow$ & Average score & 0.129 & 0 & 0.129 \\
\hline value component & $\rightarrow$ & Average score & 0 & 1.054 & 1.054 \\
\hline expectancycomponent2 & $\rightarrow$ & Average score & 0 & 0.952 & 0.952 \\
\hline Resource management & $\rightarrow$ & Average score & 0 & 0.951 & 0.951 \\
\hline cognitive metacognitive & $\rightarrow$ & Average score & 0 & 1.104 & 1.104 \\
\hline Value component & $\rightarrow$ & Motivated strategies & 0.925 & 0 & 0.925 \\
\hline expectancycomponent2 & $\rightarrow$ & Motivated strategies & 0.823 & 0 & 0.823 \\
\hline Resource management & $\rightarrow$ & Learning strategies & 0.784 & 0 & 0.784 \\
\hline Cognitive metacognitive & $\rightarrow$ & Learning strategies & 0.937 & 0 & 0.937 \\
\hline
\end{tabular}


levels of self-efficacy are associated with utilization of higher levels of learning strategies [31]. On the other hand, in a study by Nei et al., the self-efficacy was a negative predictor of stress of exam, which indicated that students who perceived an educational situation as stressful were less likely to be able to rely on their own abilities to control that situation [32].

In accordance with the SCCT performance model, self-efficacy beliefs first play an important role in the growth of intrinsic motivation, and contributing to facilitating the cognitive processes. Indeed, their improvement increases the probability of using cognitive strategies and, thereby enhancing the level of student performance. In a study by Navaro, self-efficacy was an important component in predicting the academic satisfaction and achievement of engineering students regardless of their demographic characteristics [33]. The results of meta-analysis of 167 studies on determining the factors affecting the academic achievement of students showed that self-efficacy, among other structures of learning strategies, had the strongest relationship with the CGPA of students [34].

According to SCCT, self-efficacy had a significant effect on outcome expectations. In other words, the outcomes that people expect are related to their judgment of their ability to perform their tasks. Individuals with high self-efficacy tend to be more inclined to visualize positive outcomes about their tasks. The results of a study by Lent on evaluating the factors influencing the interest in education among 600 Portuguese students suggested that self-efficacy and outcome expectations together predict interest in education, which mediates the relationships between self-efficacy and outcome expectations in choosing the future profession [7]. However, in the present study, outcome expectations were not a significant component in predicting students' academic achievement. The reason for this can be partially related to the negative expectations of students from the outcome of their field of study and the reduction of job opportunities due to the mismatch between student admissions and the needs of the community.

In this study, different learning strategies and outcome expectations did not show significant differences in terms of personal characteristics such as gender and environment, consistent with Turan et $\mathrm{Al}$. and Demirören et al. studies in Turkey $[29,30]$.

Gudaganavar et al. in a study on the study habits of 250 Indian students found that although there was no significant difference in the general habits of study between male and female students, women were significantly different from men in aspects such as taking notes at the time of study, organizing information, and preparing for tests. These habits had a direct relationship with women's academic achievement, while the use of such methods in men did not show any significant relationship with their academic performance [35].

Farooq et al. studied the learning approaches and CGPA of students. They found that females were better than males and their academic achievement had a direct relationship with the educational level of their parents [36]. Considering contradictory results of several studies in this area, further studies might give better information about the effect of personal differences including gender differences such as the role of cultural norms.

The present study's findings indicated that the increase in study hours per week and employment of students in jobs had a positive and negative impact on their academic achievement, respectively. This suggests that the quality of study and the focus on the course can directly improve the academic performance, with the simultaneous employment having a negative impact on student performance through reducing the hours of study. On the other hand, in spite of the effective role of extrinsic factors in students' academic performance, none of the personal variables studied in this research were related to the student's academic achievement. This indicates that learning strategies and motivational strategies have a role to play in determining the academic achievement of students regardless of their individual and social characteristics.

The present study for the first time investigated the academic achievement of medical students based on the SCCT theoretical model. However, as with any other research, there were some limitations. Firstly, the collected data were based on a cross-sectional design and a non-probable sampling. Secondly, as the data were gathered from a sample of one state university in Iran, thus, generalizability of the findings of this study may be limited to the target population. Finally, in spite of complete response rate to our study questionnaires, we did not explore such academic achievement's determinants of students who did not or refused to participate in this study, therefore, this problem should be considered in future studies. These limitations suggest that the study findings ought to be interpreted cautiously.

\section{Conclusions}

Knowing the cognitive and metacognitive strategies in student learning skills and identifying the most important motivational factors and goals in the success of their academic achievement can contribute to better understanding of these strategies and factors affecting the performance of students by lecturers and educational planners. Further, all faculty members and lecturers in the medical education should be familiarized with the ways to enhance active learning skills and be encouraged to involve students in the teaching-learning process and to use interactive teaching patterns. Therefore, medical 
teachers should recognize their students' motivations and prevailing learning strategies, monitor their learning in their academic environment, and encourage them to be engaged in learning.

\section{Additional file}

Additional file 1: Raw data. (SAV $78 \mathrm{~kb}$ )

\section{Abbreviations}

CGPA: College grade point average; MSLQ: Motivational strategies for learning questionnaire; SCCT: Social Cognitive Career Theory; SEM: Structural Equation Modeling; SLSP: Skills Learning Support Program; SOES: Student outcome expectations scale; UAE: United Arab Emirates

\section{Acknowledgements}

This study was approved by the research deputy of Shahid Beheshti University of Medical Sciences with the ethics code of

IR.SBMU.PHNM.1395.406. Hereby, the researcher appreciates the collaboration of the research deputy of Shahid Beheshti University of Medical Sciences and all the students who participated in this study.

\section{Funding}

A part of the present research (as student grant) was funded by Deputy of Research, Shahid Beheshti University of Medical Sciences.

\section{Availability of data and materials}

Most of the analyzed data of this study are included in this article. The datasets used and analyzed during the current study are available from the corresponding author on reasonable request. However, the raw data file is available for review by the Editor or statisticians of this journal as supplementary file.

\section{Authors' contributions}

SN performed data collection and drafting the manuscript, final check the manuscript. SH designed the research and its concept, revised manuscript critically for important intellectual content. She was a major contributor in writing the manuscript. $\mathrm{ZSH}$ revised and final checked the manuscript and was a major contributor in couseling the research method. FR analyzed and interpreted the data regarding the research questions. All authors read and approved the final manuscript.

\section{Ethics approval and consent to participate}

To comply with ethical considerations, the research project was approved by the Ethical Research Committee of Shahid Beheshti University of Medical Sciences under the ethics code IR.SBMU.PHNM.406. The study respected the principles of the ethics committee in charge as well as the 1975/1983 Helsinki declaration.

Written informed consent to enter the study was obtained from the participants and was ensured about the confidentiality of their data and their right to withdraw from the study at any time and was ensured that their withdrawal would not affect routine utilization services (a copy of consent form is available as supplementary file)

\section{Consent for publication}

All students participating for the present study sign a statement confirming that their data will be used anonymously for research objectives. A copy of the consent form is available for review by the Editor of this journal and has been available as supplementary file.

\section{Competing interests}

The authors declare that they have no competing interests.

\section{Publisher's Note}

Springer Nature remains neutral with regard to jurisdictional claims in published maps and institutional affiliations.

\section{Author details}

'Student Research Committee, Department of Midwifery \& Reproductive Health, School of Nursing \& Midwifery, Shahid Beheshti University of Medical Sciences, Vali Asr Ave., Ayatollah Rafsanjani Cross Road, Niayesh Complex, Tehran Zip code: 1985717443, Iran. ${ }^{2}$ Department of Midwifery and Reproductive Health, Faculty of Nursing and Midwifery, Shahid Beheshti University of Medical Sciences, Tehran, Iran. ${ }^{3}$ Department of biostatistics \& epidemiology, Arak University of Medical Sciences, A'lam-Al-Hoda Street, Shahid Shiroodi Street, Arak, Markazi Province Zip Code: 3819693345, Iran.

Received: 3 October 2018 Accepted: 19 March 2019

Published online: 05 April 2019

\section{References}

1. Wibrowski CR, Matthews WK, Kitsantas A. The role of a skills learning support program on first-generation college students' self-regulation, motivation, and academic achievement: a longitudinal study. J Coll Stud Retent. 2017;19(3):317-32.

2. Fong CJ, Davis CW, Kim Y, Kim YW, Marriott L, Kim S. Psychosocial factors and community college student success: a meta-analytic investigation. Rev Educ Res. 2017;87(2):388-424.

3. Liew SC, Sidhu J, Barua A. The relationship between learning preferences (styles and approaches) and learning outcomes among pre-clinical undergraduate medical students. BMC Med Educ. 2015:15(1):44.

4. D'Antoni AV, Zipp GP, Olson VG. Interrater reliability of the mind map assessment rubric in a cohort of medical students. BMC Med Educ. 2009; 9(1):19.

5. Soemantri D, Mccoll G, Dodds A. Measuring medical students' reflection on their learning: modification and validation of the motivated strategies for learning questionnaire (MSLQ). BMC Med Educ. 2018 Dec;18(1):274.

6. Schmeck RR, editor. Learning strategies and learning styles. Southern Illinois University. New York: Springer Science \& Business Media; 1988.

7. Lent, R. W., Brown, S. D. and Hackett, G. 1994. "Toward a unifying social cognitive theory of career and academic interest, choice, and performance" [Monograph]. J Vocat Behav 45:79-122.

8. Credé M, Roch SG, Kieszczynka UM. Class attendance in college: a metaanalytic review of the relationship of class attendance with grades and student characteristics. Rev Educ Res. 2010;80(2):272-95.

9. Poropat AE. A meta-analysis of the five-factor model of personality and academic performance. Psychol Bull. 2009;135(2):322.

10. Caprara GV, Fida R, Vecchione M, Del Bove G, Vecchio GM, Barbaranelli C, Bandura A. Longitudinal analysis of the role of perceived self-efficacy for self-regulated learning in academic continuance and achievement. J Educ Psychol. 2008:100(3):525.

11. Ashman AF, Conway RN. Cognitive strategies for special education: process based instruction. London: Imprint Routledge; 2017.

12. Schunk DH, Zimmerman B. Handbook of self-regulation of learning and performance (Educational Psychology Handbook). 2nd edition. New York and London: Routledge, Taylor and Francis

13. Sitzmann T, Ely K. A meta-analysis of self-regulated learning in work-related training and educational attainment: what we know and where we need to go. Psychol Bull. 2011;137(3):421.

14. Muwonge $\mathrm{CM}$, Schiefele U, Ssenyonga J, Kibedi H. Modeling the relationship between motivational beliefs, cognitive learning strategies, and academic performance of teacher education students. S Afr J Psychol. 2018; 18:0081246318775547.

15. Bandura A. The explanatory and predictive scope of self-efficacy theory. J Soc Clin Psychol. 1986;4(3):359-73.

16. Al-Harthy IS, Was CA, Isaacson RM. Goals, efficacy and metacognitive selfregulation a path analysis. Int J Educ. 2010;2(1):1.

17. Nokhostin Goldoust A \& Moeinikia M. The study of Relation between SelfRegulated Learning Strategies and Motivation Strategies with students' academic performance. Curriculum Planning Knowledge \& Reasearch in Educational Sceinces. Islamic Azad University (Isfahan). 23, 85-100.( In Persian).

18. Kizilcec RF, Pérez-Sanagustín M, Maldonado JJ. Recommending selfregulated learning strategies does not improve performance in a MOOC. In Proceedings of the third (2016) ACM Conference on Learning@ Scale 2016 Apr 25 (pp. 101-104). Edinburgh: ACM; 2016.

19. Cho KK, Marjadi B, Langendyk V, Hu W. The self-regulated learning of medical students in the clinical environment-a scoping review. BMC Med Educ. 2017;17(1):112. 
20. Pintrich PR, Smith D, Garcia T, McKeachie WJ. A manual for the use of the Motivated Strategies for Learning Questionnaire (MSLQ). Ann Arbor, Mich, USA: National Center for Research to Improve Postsecondary Teaching and Learning, University of Michigan; 1991.

21. Duncan TG, McKeachie WJ. The making of the motivated strategies for learning questionnaire. Educ Psychol. 2005;40(2):117-28.

22. Betz NE, Voyten KK. Efficacy and outcome expectations influence career exploration and decidedness. Career Dev Q. 1997;46(2):179-89.

23. Stoffa R, Kush JC, Heo M. Using the motivated strategies for learning questionnaire and the strategy inventory for language learning in assessing motivation and learning strategies of generation 1.5 Korean immigrant students. Educ Res Int2010 Dec 27; 2011.

24. Taheri Z, Delavar A, Ghadampour E, Farokhi N. Factors influencing on the proper model of motivational beliefs in high school students, Tehran, Iran. J Fundamentals Ment Health. 2010;4(48):662-73.

25. Pintrich PR, Smith DA, Garcia T, McKeachie WJ. Reliability and predictive validity of the motivated strategies for learning questionnaire (MSLQ). Educ Psychol Meas. 1993;53(3):801-13.

26. Shafi naderi M, Kodivar P, Arab zadeh M, Sorami G. An analysis of the factor structure reliability and validity of students outcome expectancy scale. Educ Meas. 2012;3(10):21-36.

27. Mukhtar F, Muis K, Elizov M. Relations between psychological needs satisfaction, motivation, and self-regulated learning strategies in medical residents: a cross-sectional study. MedEdPublish. 2018;7.

28. Griffin R, Mackewn A, Moser E, VanVuren KW. Learning skills and motivation correlates to superior academic performance. Bus Educ Accredit. 2013;5(1): 53-65.

29. Turan S, Demirel Ö, Sayek I. Metacognitive awareness and self-regulated learning skills of medical students in different medical curricula. Med Teach. 2009;31(10):e477-83.

30. Demirören M, Turan S, Öztuna D. Medical students' self-efficacy in problembased learning and its relationship with self-regulated learning. Med Educ Online. 2016;21(1):30049.

31. Kek MY, Huijser H. The power of problem-based learning in developing critical thinking skills: preparing students for tomorrow's digital futures in today's classrooms. High Educ Res Dev. 2011;30(3):329-41.

32. Nie Y, Lau S, Liau AK. Role of academic self-efficacy in moderating the relation between task importance and test anxiety. Learn Individ Differ. 2011;21(6):736-41.

33. Navarro RL, Flores LY, Lee HS, Gonzalez R. Testing a longitudinal social cognitive model of intended persistence with engineering students across gender and race/ethnicity. J Vocat Behav. 2014;85(1):146-55.

34. Richardson M, Abraham C, Bond R. Psychological correlates of university students' academic performance: a systematic review and meta-analysis. Psychol Bull. 2012;138(2):353.

35. Gudaganavar NV, Halayannavar RB. Influence of study habits on academic performance of higher primary school students. Int I Sci Res. 2014;277(3): 280

36. Farooq MS, Chaudhry AH, Shafiq M, Berhanu G. Factors affecting students' quality of academic performance: a case of secondary school level. J Qual Technol Manag. 2011 Dec;7(2):1-4.

Ready to submit your research? Choose BMC and benefit from:

- fast, convenient online submission

- thorough peer review by experienced researchers in your field

- rapid publication on acceptance

- support for research data, including large and complex data types

- gold Open Access which fosters wider collaboration and increased citations

- maximum visibility for your research: over $100 \mathrm{M}$ website views per year

At BMC, research is always in progress.

Learn more biomedcentral.com/submissions 